A Critical Race Theory framework for Education Policy Analysis: the case of bilingual learners and assessment policy in England

\author{
Alice Bradbury \\ UCL Institute of Education, University College London, London, UK \\ UCL Institute of Education, \\ University College London, \\ 20 Bedford Way \\ London WC1H 0AL \\ a.bradbury@ucl.ac.uk \\ @alicejbradbury
}




\section{A Critical Race Theory framework for Education Policy Analysis: the case of bilingual learners and assessment policy in England}

This paper combines tools from policy sociology with those from Critical Race Theory (CRT) to build a framework for a CRT-based education policy analysis, based on a set

of questions about the relationship between policy and racial inequalities. Drawing on a case study of assessment policy in England, the paper examines how tools from both bodies of scholarship can be used to interrogate the motivations, results and assumptions implicit in policy. The policy used as an illustration is the introduction of Baseline Assessment, which was conducted in the first weeks of school at age four/five for the purposes of measuring progress seven years later. This policy failed to take into account the needs of bilingual learners (or children with English as an additional language in UK terminology). It is argued that this absence provides an example of how policy can serve to continue white dominance while appearing neutral and meritocratic. 


\section{Introduction: Policy and 'race'}

A government wants to know how effective its primary schools are, but the system of simply measuring outputs in the form of test results has been criticised, because it fails to take into account the different intakes of children coming into the schools. So, the government decides to measure children when they enter school, and then compare this to the test results, so that schools' value added can be compared. There is already an assessment at the end of the first year of school, so doing another one at the start is not a huge change. The problem is, the existing assessment takes a whole year to compile as it is done through observation and, for children who do not speak English, the assessment can be done in a home language. This new assessment has to be done quickly, and entirely in English. Children who do not speak English do not understand the instructions, and what they say about numbers, letters or the world around them in their own language is not recognised on this assessment. This means that these pupils, who come mainly from minoritised communities, score very low, if they get a score at all. So, when these children leave the school, if their test results are high, the school will look like it has added a lot of value. But if the scores for these children are low, no one will worry, as they will still have made the right level of progress. The low expectations of the English-language learners are established right at the very start of their school careers, and stay with them though their seven years in primary school, solidified in the data which tracks them as they progress.

This paper begins with this story, which is a description of events in England in 2015-16, as an illustration of why policy requires analysis in terms of racial inequity. When the UK government attempted to introduce a new 'Baseline assessment' for the purposes of measuring progress through primary schools in England, the vast majority of the uproar that resulted related to the impact on young children overall. Yet this was a policy which potentially discriminated against children with English as an additional language (EAL learners) by establishing low expectations in their first weeks of school, in contrast to the existing assessment which at least attempted to recognise learning as demonstrated in home languages. This policy was abandoned in 2016, but has since been re-introduced, with a new version of Baseline statutory in 2020, with again no significant consideration for the impact 
on EAL learners. This paper uses this example to illustrate how policy analysis can combine ideas from policy sociology and Critical Race Theory, resulting in a framework for conducting such a CRT Policy analysis, in the form of a number of questions to be asked of policy.

Critical Race Theory (CRT) has become almost the default theoretical position for those researching 'race' and education in England, largely due the effective promotion of this perspective in Gillborn's important work on 'race' and education in the UK (Gillborn 2008, 2013b), and the versatility of its tools and approaches (for example, Bradbury 2013; Chadderton 2015; D'Arcy 2014; Warmington et al. 2018). However, those scholars using CRT in exploring education policy specifically vary in their application and use of CRT, and the question of what is distinct about a CRT policy analysis remains. While there is a wealth of CRT-based literature from the US context on particular policy agendas (for example, Parker 2003; Scott 2011; Scott \& Holme 2016; Chapman \& Donnor 2015), and some discussion of the use of CRT in critical policy analysis (Atwood and Lopez, 2014), the different political context of the UK and the 'local racial formulations' (Bonilla-Silva 2015, p. 82) require some consideration of a CRT-informed policy analysis that could be applied in wider contexts.

Moreover, studies involving UK policy are often also informed by tools from policy sociology, particularly Ball's work (Ball 2013b, 2013a; Ball 1993) which draws on Foucault and his examination of the operation of power (1980). With these issues in mind, this paper seeks to tentatively offer a framework for what a CRT policy analysis in education might look like, using a case study from policy in England as an illustration. The first section describes the contributions of policy sociology and CRT to their relative fields, and discusses how CRT has been used to examine policy internationally. Then a series of questions and sub-questions which might form a CRT policy analysis are set out, before the case study is 
explained and the framework is used to analyse it. Throughout, the aim in building a framework is to re-centre the issue of 'race' in studies of policy, at a time when it is too frequently an 'absent presence' (Apple 1999). For the purposes of this paper, 'policy' is defined broadly, bearing in mind the 'theoretical uncertainties about the meaning of policy' (Ball 1993, 10).

\section{Policy sociology}

Sociological analyses of policy - most notably Stephen Ball's work - consider policy as a process rather than a fixed text, with discursive power in the constitution of particular 'problems' and 'solutions' (Ball 1993). As Rizvi and Lingard summarise, Ball's view of policy analysis 'involves the decoding of texts, in relation both to their context in which they are embedded and the context they construct, and to the effects they have on practice, linked to broader social effects' $(2009,12)$. Policy is not an outcome but a process, 'ongoing, interactional and unstable' (Ball 2013b, 8). Within post-structural analysis, drawing on Bowe, Ball and Gold's policy cycle (1992), 'policy is understood to be produced and productive multiply and iteratively in non-linear processes across contexts of influence, text production and practice' (McGimpsey, Bradbury, and Santori 2017, 909, emphasis added). Policy is produced is complex ways, but also produces in multiple, sometimes contradictory ways. Relevant here is the production of subjectivities - the 'underachieving student', the 'disadvantaged' child, the 'troubled family' - while at the same time policy is being produced through debates about what matters and what and who needs to be 'solved'. As Braun et al argue, the 'primary discourses of policy [ ] produce particular kinds of teacher and student subjects - good teachers and good students' (Braun, Maguire, and Ball 2012, 138). Thus post-structural accounts of policy consider the constitution of the subjects named by and represented within policy, at all stages of the policy cycle. 
A 'policy as discourse' approach, drawing on Foucault's notion of discourse, considers how policy has its 'own specific rationalities, making particular sets of ideas obvious, common sense and 'true'" (Ball 2013b, 6-7). For example, the idea that bilingual students are a 'challenge' for schools is made normal through policy documentation which lists how they should be supported. Policy establishes and re-inscribes particular 'regimes of truth' about what matters in education, and who can be recognisable as successful or failing. These ideas and approaches from policy sociology are important and influence how many working with Critical Race Theory analyse policy, as I discuss below. They operate within a broader international field of critical policy analysis (CPA), which draws on critical theory in forms of analysis that consider the operation of power, the marginalisation of some voices and perspectives and the differences between rhetoric and reality (Diem et al. 2014).

\section{Critical Race Theory and policy}

CRT, as well rehearsed elsewhere (Ladson-Billings 2004; Tate 1997; Taylor, Gillborn, and Ladson-Billings 2009; Delgado and Stefancic 2000(Bonilla-Silva 2015) offers an understanding of society as shaped by racism which is endemic, systematic and often unrecognised. It offers a lens through which to consider the 'business as usual' (Delgado and Stefancic 2000) operation of 'race' as a social construct which has discursive and material effects on individuals, institutions and in policy. In terms of policymaking, CRT provides a framework through which to consider how racial inequality is maintained by policies which systematically discriminate against minoritised groups, including, as relevant to the case discussed here, those that do so by failing to provide for those who speak different languages (Yosso 2005; Mitchell 2010). Frequently, these are policies which appear 'colourblind' or neutral and meritocratic, but work to systematically disadvantage minoritized groups. As House succinctly puts it, the 'operation of the system as a whole has racial consequences 
even if those administering it do not have that in mind' (1999, p. 11).

The CRT principle of interest convergence (Bell 1992), which describes how progress for minoritized groups only occurs when it is also in the interest of white elites, provokes an analysis of policy based on recognition that policy is always a compromise between competing interests. This has been used extensively to critique the formulation of policy which appears to remedy racial injustices (for example, Gillborn, 2010).

In the UK, CRT perspectives have more recently been used to examine how issues relating to 'race' in education have rarely been the priority of governments, despite occasional moments of rhetorical concern; for decades, there has been a constant need to 'fight for legitimacy as a significant topic' for policy (Gillborn 2005, 493). Indeed, under the Conservative-Liberal Democrat coalition government (2010-15) - the period where the policy under discussion here developed - concern for 'race' was 'severely diminished' (Warmington et al. 2017). This period followed some unproductive interest in issues of racial inequity in the 2000s under a Labour government, in the wake of the Macpherson inquiry into the killing of Black teenage Stephen Lawrence, which reported in 1999. At the time of writing (2018), it remains to be seen if the interest of Theresa May's government in racial inequality, as indicated by the 'race audit' (UK Government 2017) and announcement of a national Stephen Lawrence Day (BBC News, 2018), is equally unproductive.

Furthermore, CRT encourages us to think of policy in terms of benefits and outcomes; as Gillborn (with colleagues) has repeatedly pointed out the benefits of 'rising standards' for different ethnic groups have not been equal in the UK (Gillborn 2008; Gillborn et al. 2017; Gillborn 2005). In this way, there are parallels between the imperatives arising from CRT, and the focus in critical policy analysis on policies as 'socially constructed products shaped by historically contingent power differentials' (Young and Diem 2014, p. 1064). In particular, CRT perspectives require examination of the impact on racial inequalities, as systems are 
reformed and new accountability measures are introduced. For example, Warmington et al. (2018) note that every shift in the measuring system of secondary education has had the effect of reintroducing the Black/White achievement gap. The CRT contribution to this work lies primarily in the consideration of how policy is a tool for the continuation of white dominance, not a neutral bystander. This work is also part of a new development in the use of CRT in education - QuantCrit - which is premised on the argument that 'numbers are not neutral and should be interrogated for their role in promoting deficit analyses that serve White racial interests' (Gillborn et al. 2018, p. 158).

Similarly, in primary education, CRT has been used to consider the operation of new assessments which are conducted through teacher assessment, which thus allow for different expectations of children from minoritized and low income families to become solidified as lower assessment results (Bradbury 2011b). In this work concepts and presentational tools from CRT are used to explore how assessment operates as a self-reinforcing mechanism for maintaining disparities in attainment at age five. This research suggested that it is public knowledge that 'disadvantaged' groups receive lower results, and thus these lower results become the only intelligible results possible for teachers to record; if teachers in inner city schools score their 'difficult intake' above the national average, they are encouraged to alter results (Bradbury 2013). This system operates to systematically disadvantage children from minoritised and lower income backgrounds, who are constituted as inevitably low-attaining.

This work is unusual because, although the use of CRT in analyses of racial inequality in the education system in the UK is growing, its use in primary and early years education remain limited. This is perhaps because, to paraphrase Ladson-Billings' question, many wonder what CRT is doing in a 'nice field' like early years education (2004). Talking about racial inequality is a difficult subject for many in the white-dominated field of education (Leonardo 2004) and this difficulty is seemingly intensified when discussing younger 
children. However, I would argue that early childhood research requires the critical standpoints provided by CRT as much as any other sector, because it is in these early years of education that children's educational trajectories are established. The current culture of tracking, predicting and target-setting in education means that how children are assessed and labelled in their first years of schooling (Bradbury and Roberts-Holmes 2017), means that what happens in these first years of education is vital to understanding overall disparities.

However, it is not only policies related to assessment that have had a negative impact on minority students in the UK; policies such as Academisation - where schools convert to being independently run from central government, with their own admissions systems and school policies - have had an impact on Black attainment and have thus been scrutinised through a CRT lens (Gillborn 2013a). Black students are less likely to achieve expected standards in Academies than in comparative schools (Gillborn 2013a), but this 'Academy penalty' is not suffered by students in the white or Asian ethnic group categories. Scholarship on new teacher training routes has also used a CRT framework to consider policy as an expression of white power and a tool for the continuation of white dominance (Chadderton 2014).

As well as building on CRT scholarship I also draw here on Leonardo's work on policy as 'acts of whiteness' (Leonardo 2007), particularly the use of race-neutral discourse as problematic. In his work on the No Child Left Behind Act in the US, he argues that this legislation exemplifies 'colorblind' ideology, in which 'success (or more important, failure) is conceived as individual or cultural' rather than structural $(2007,265)$.

This attempt to build a framework is based on and indebted to the scholarship of others - those referenced above and more widely - who provide examples of how analysing policy using CRT is done (see for example, Parker 2003; Scott 2011; Atwood and López 2014; Scott \& Holme 2016; Chapman \& Donnor 2015). In many ways this framework 
replicates their work, but it nonetheless seems worthwhile to draw together CRT work with the distinctive approaches offered by policy sociology into a structure which guides how we think about policy and racial inequality at all stages of the policy cycle.

\section{A framework for a CRT education policy analysis}

Policy matters for those interested in inequalities because it 'shapes who benefits, for what purposes and who pays' (Bell and Stevenson 2006, 9). Although Bell and Stevenson referred to 'who pays' in monetary terms, we could equally consider 'who pays' as who is disadvantaged by the policy. Bringing the impact on the marginalised to the forefront of the analysis alters the questions we ask of policy. For instance, Gale (1999) argues policy analysis focuses on the 'what', 'how' and 'why' of policy. Meanwhile, using a CRT perspective, Gillborn has used three questions as prompts: who drives policy and who does it prioritise, who benefits from the policy, and what are the effects? (Gillborn 2005, 492). Building on these three questions, here I contend that a 'race'-centred policy analysis would benefit from some direct and disruptive questions focused on racial inequalities (and similarly, this could be applied to other forms of inequity, which I do not have space to consider here). An acceptance of racism as endemic leads us to reframe the question of 'Who gains?' as 'How do white people gain?'. This re-orientates the focus from proving that white people gain, to examining how they gain; this is a more in-depth question which is more likely to reveal and disrupt racial inequality. However, the focus should not only be on whites; the question 'How does this damage or disadvantage minoritized groups or individuals?' is also needed, as gain for one group does not relate simply to loss for another. We also need to ask 'How does this disadvantage one group more than another? What is the purpose of this?' 
The question of who is prioritised within policy can be framed as 'How is white dominance prioritised?'; if we take on board the concept of interest convergence (Bell 1992) then we recognise that even legislation which appears to prioritise minoritised groups does so in a way which somehow benefits whites. And finally, Gillborn's question of what drives policy, in keeping with the tenet of CRT that racism is endemic and the driving force behind seemingly neutral actions, can be rephrased as 'How does this maintain/continue/reinforce white dominance?'.

So, what does policy sociology add to these questions? I would argue that these issues need to be considered differently in the three different stages of Bowe, Ball and Gold's policy cycle (1992): the context of influence, the context of text production, and context of practice ${ }^{\mathrm{i}}$. We cannot assume that the operation of racial dynamics will be consistent in all of these contexts, nor that they will be as significant; to consider only one context would be to ignore the role of the others in reproducing inequality. This leads on to the production of specific questions, under these broader questions, for each of the three contexts, as shown in Table 1.

[Table 1 here]

\section{Context of influence}

The context of influence is the area where policy develops, where various actors, including politicians and lobbyists, operate (Bowe, Ball, and Gold 1992). Before becoming legislation, policy is formulated in speeches, opinion pieces, manifestos and public consultations; this context is one of contestation and debate. However, we need to recognise that there is a 'policy creation community' (Mahoney et al, 2004 Rizvi and Lingard 2009, 15) who produce policy 'problems' and their related 'solutions', and thus the subjects of policy. In education (and more widely) this is an increasingly globalised policy creation community, influenced at the supra-national level by organisations such as the OECD and World Bank (Rizvi and 
Lingard 2009; Sellar and Lingard 2014), though the much power still remains at the level of the nation state. It is also a group which is in flux, open to the influence of 'new knowledges' from academic research, with the potential to establish new sites of policy intervention (McGimpsey et al 2017).

In this context of influence, particular regimes of truth are established, about where policy should intervene, and how, and what should be omitted from legislative plans. Thus the questions related to this context relate to the ideas that are introduced, contested and established, and who are the beneficiaries or victims of these ideas in wider terms. It is important to question how policy discussions are framed by racial equity as a priority issue, or as a distraction from the 'real concerns' (as 'white working-class underachievement' is framed in the UK), and how the creation of a 'problem' is explicitly or implicitly linked to 'race'. We should consider how the creation of one 'problem' can operate as a diversionary tactic, drawing attention away from concerns of racial equity and allowing the concerns of marginalised groups to be forgotten. What is omitted in policy - the 'policy silences' may be as important as what is included; similarly, particular voices may be silenced in the debate. Finally, in this context, how do the discursive moves made by those seeking to influence policy present themselves as 'colorblind' or race neutral, or as sympathetic to the cause of racial equity, and what effect does this have? This question relates to the 'rules of racial standing' (Bell 1992) which encourage us to think about how who is speaking affects the reception of their arguments, and in turn the motivation of those who speak and promote others to speak. Furthermore, the CRT concept of interest convergence (Bell 1992), encourages the policy analyst to think about how even seemingly progressive moves may in fact benefit whiteness. This is important at all stages of the policy cycle, but in this context it may be more visible as a broader range of ideas are presented. 


\section{Context of text production}

The context of text production considers the way in which the policy is presented, 'mediatised' (Rizvi and Lingard 2009, p19), or 'spun' (Gewirtz, Dickson, and Power 2007) so that particular key messages are emphasised. Policy evolves through its presentation and regurgitation in related texts, such as newspaper reports, reactions from key organisations and campaign groups, and publications aimed at the professionals who will use the policy, such as 'What you need to know about...' style texts. Again this is a context marked by contestation, where 'the representation of the meaning of policy is a competitive process in relation to who controls the text production' (Lightfoot 2015, 85).

There are some similar questions to be asked at this stage from the context of influence: how are particular groups or individuals presented through policy, as problems or part of solutions? If policy is presented as 'colorblind' or race neutral, how does this delegitimise those who challenge policy on the grounds of equity? Policy can be co-opted by the unintended beneficiaries, to prove a point. This context is also an area where particular groups can be pathologized as problematic, even where the policy is not directly related to these communities. For instance, policy on school testing which references the specificities of the 'urban school' or notes the challenges of teaching 'disadvantaged' populations, reproduces the minoritized and poor students of the city as deficient and 'difficult' subjects.

\section{Context of practice}

This final context is where is policy is implemented, interpreted or enacted - remade in different places by different policy actors. Research in schools in England has suggested that how policy is enacted is dependent both on the context of the institution, for example their position in league tables (Braun et al. 2011), and on the operation of policy actors such as 'policy entrepreneurs' and those that resist (Ball et al. 2011). 
Bearing these mitigating factors in mind, we need to explore how policy has an impact on pedagogy and practice, for example on how classrooms are organised, and what is taught and by whom and where. These every-day practices, as research has consistently found, have an important part to play in reproducing inequalities of attainment and experience (Bradbury 2013;Campbell 2015; McGillicuddy and Devine 2018). Furthermore, given the importance of assessment results in a data-driven, accountability-based system, we must link these practices to the production of disparities in attainment. For example, rational and seemingly 'colourblind' processes like the prioritisation of borderline pupils can operate to further disadvantage minoritised students (Gillborn and Youdell 2000). We need to consider how policy is enacted in ways which encourage the use of stereotypes, dividing practices or labelling, which have been shown to disadvantage minoritised students (Campbell 2015; McGillicuddy and Devine 2018). Finally, while analysing enactment is always context- and policy-specific - the policy might be focused on areas other than the classroom, such as leadership - there should be some questioning of how either the absence or indeed presence of 'race' and proxies for racialized groups in policy perpetuates inequalities and the dominance of whiteness. Where 'race' is explicitly included - for example where 'ethnic minorities' are listed as a problem group to be considered specially how does this presence operate to further distance minoritised children from an idealised white norm?

\section{Building a framework}

These elements form a framework for analysing policy using a CRT lens - as illustrated in Table 1. It is not anticipated that this form of analysis will necessarily involve all of the questions or all three contexts; these should not be seen as 'boxes to be filled in', but spaces for asking critical questions, or ways in to thinking about a particular policy. As stated, the questions may not work in all cases, or there may be more questions to ask. 
Suggestions for further important questions would be welcome. This is a starting point, an attempt to draw together different approaches to produce a tool to provoke a different way of thinking about policy.

Below, a case study of Baseline policy in England and EAL learners provides an example of how this framework could be used. For reasons of space this discussion focuses more on the final context of practice, but some preliminary ideas as to how the case could be considered in the first two contexts are provided.

\section{The case of Baseline Assessment}

Unlike many education systems around the world, the school system in England assesses children from the very start of their compulsory education, by law. Children have to attend school in the academic year in which they turn five, and during this 'Reception' year they are assessed by their teacher on seventeen 'early learning goals', which form the Early Years Foundation Stage Profile (EYFS Profile). Attainment data from this assessment reveal marked disparities in attainment based on deprivation indices, gender, and 'ethnic group' (the term used to by government to categorise children) (DfE 2016). Research on the conduct of this assessment has suggested a system of reinforcement between low results and low expectations, with teachers in schools with disadvantaged and high minority populations being expected to judge children as lower attaining (Bradbury 2011b, 2013). However, in 2015 a new system of assessing children at the start of Reception was introduced, with the aim of providing a 'baseline' for future measures of progress, to operate alongside the EYFS Profile. This new assessment, known as Baseline Assessment, was based on the idea that 'progress' can be measured between two assessment points, and this can be used to judge the 'value added' to children by schools. Baseline, as the name suggests, is the starting point for a measure of progress made by children through primary education, between their entry at 
age four and exit at age 11, when they take statutory assessment tests (SATs). This policy move is part of a wider 'reification of progress' (Bradbury and Roberts-Holmes 2017) as a way of judging schools, also seen in the move to use the Progress 8 measure in secondary schools. 'Value added' measures are often seen as more sympathetic to schools which have a lower-attaining intake on entry, and as disruptive of league tables which focus purely on attainment (Bradbury 2011a). They can be seen as allowing some schools' positive work with under-privileged communities to be recognised; however, there are some issues with any measure of 'value added' which are important to recognise, and I outline them briefly here for the purposes of context. First, there is an assumption of linear progress, which is questioned by many in the early childhood education community (Moss et al. 2016). Young children's learning is unpredictable and complex, which results in the second problem of accurate assessment. Secondly, there is a great deal of debate about the possibility of an accurate assessment of any skill or tendency at this age (Jarvis 2017). Third, there is the problem of prediction, as Baseline in comparing results seven years later with the test at four/five, inherently involves some form of prediction of expected progress. Furthermore, the content of the assessments varies, which produces further issues with expectation. Finally, there is the social justice impact of an assessment, which some parents may prepare their children for, thus setting up differential expectations which follow children through their school years (Bradbury and Roberts-Holmes 2017). It is this final issue which I examine in more detail in later sections. One of the notable features of all three forms of Baseline Assessment promoted by the government was the absence of any provision to conduct the assessment in languages other than English, in contrast to existing assessments for this age range which can be conducted in home languages (DfE 2017).

Baseline Assessment was introduced in 2015 in a short-lived policy foray into using children's scores on entry to school as a starting point for measures of school quality (an 
attempt due to be repeated in 2020). Although the use of this assessment was problematic for a number of reasons, the issue of engendering low expectations for children with English as an additional language (EAL) has received little attention thus far. To be clear, Baseline could not be conducted in any language other than English, leaving EAL learners with very low scores. Here some of the questions in the framework above are considered in relation to the three contexts, with a greater focus on the context of practice, after a brief discussion of the wider context of EAL policy.

\section{The label ' $E A L$ '}

It is important to be clear that I am aware of the danger of homogenising the group of children labelled by the system as 'EAL'. This is a diverse group made up of children from a range of nationalities, different socio-economic backgrounds and with different levels of exposure to English. A child's registration on official school census data as EAL relies only on the parent writing a language other than in English as home language on a form; there is no official distinction between children who speak no English at all, and those who are balanced bilinguals. Moreover, the distinction between who is labelled EAL and not is increasingly irrelevant as linguistic diversity increases: as Leung et al wrote twenty years ago, 'the binary native-speaker-versus-other is increasingly redundant' (Leung, Harris, and Rampton 1997, 557-8).

It is also important also to note that EAL learners cannot be conflated with minoritised students, as many EAL learners are white, and many children from minoritised groups speak English. According to the national association for EAL teachers, there are a growing number of children in primary education in England who are recorded as EAL: in 2016 the proportion was over $20 \%$ compared to under $13 \%$ in 2006 (NALDIC n.d.). This is 
due to the increase in migrants from the European Union and the younger demographic profile of many minoritised communities in the UK.

Research on these children's experiences suggests that school cultures which prioritise English may cause children to see their language as 'inferior, undesirable or illicit' (Welply 2017; see also Tereshchenko 2014). Studies involving Eastern European EAL children suggest that they may also fear of being bullied because of their different language (Liu and Evans 2016); this indicates that whiteness is not a protection against discrimination based on language (Mitchell 2013).

Thus the term 'EAL' must be seen as an official label which has material and social real-life effects, without providing much more information than revealing what was written on a form. The following analysis keeps this in mind when examining how policy disadvantages EAL learners, in the knowledge that not all are affected in similar ways or to the same extent.

\section{The context of influence}

Using the policy cycle as a structure for analysis requires recognition that each of the contexts has elements which are private and public, which we have differing degrees of access to, and that there may be some overlap between the contexts. Despite this recognition that the sources may only be partial, if we think first about the context of influence, we can begin with the contemporary pattern of assessment policy regarding EAL learners which will have shaped the formation of Baseline.

The existing (and continuing) assessment in Reception, the EYFS Profile, can be conducted in languages other than English, for the parts of the assessment other than communication, language and literacy skills.

For children whose home language is not English, providers must take reasonable steps to provide opportunities for children to develop and use their home language in play and 
learning, supporting their language development at home. Providers must also ensure that children have sufficient opportunities to learn and reach a good standard in English language during the EYFS: ensuring children are ready to benefit from the opportunities available to them when they begin Year 1. (DfE 2017)

Thus, a culture exists which (at least nominally) recognises that EAL children have language skills which should be acknowledged and developed in Reception, where possible, by the use of staff who speak children's languages. The professional association for EAL, NALDIC, a key influencer in this area concurs: their work 'highlights the critical role of monolingual and bilingual practitioners' (NALDIC n.d.). However, another aspect of the policy context of influence appears to have been dominant in the discussions leading up to Baseline policy: the dominance of a positivist discourse of measurement, where assessment is a neutral tool to be used in 'colourblind' ways. As stated by the DfE in the consultation document (DfE 2015), the purpose of Baseline was to provide a measure of school effectiveness, suggesting that the policy is influenced by economic models of input and output which fail to take into account the complexity of learning and the social context in which assessments take place (Moss 2014). This in turn leads to the need for a 'simple' assessment and the creation of a 'true baseline', which allows all of the school's input to be registered on 'value added' measures. This is a discourse of datafication, which does not take account of children speaking different languages (Bradbury and Roberts-Holmes 2017).

Detailed analysis of this context remains difficult without access to private discussions and documents or retrospective elite interviewing, but, if we return to the questions in the framework above we can see how at this stage, white dominance is prioritised through the positioning of Baseline policy as 'race neutral', treating all children the same. This is facilitated by the idea that the assessment must be quick and simple. There is no recognition that structural factors may disadvantage EAL children, and the voices of those who advocate for EAL children are ignored, so that the policy damages marginalised 
groups. White people gain in that they do not appear 'racist', but neither are they accused of 'political correctness' in creating particular conditions of assessment for EAL children.

\section{The context of text production}

The second context of text production is also quite opaque, however we can consider how the issue of EAL pupils and Baseline is presented in official documentation. To return to the framework questions, it is possible to use texts to consider how Baseline constitutes EAL children as a 'problem' within the system. For example, in this guideline for companies wishing to produce a government-approved Baseline Assessment, the issue of EAL children is mentioned specifically:

The Provider must demonstrate that the assessment does not unduly discriminate against sub-groups of the population such as gender, ethnicity, disability, etc. [...] A particular focus should be given to pupils with English as an additional language (EAL) to ensure that the progress measure is not unduly beneficial to schools with high proportions of EAL children. (STA 2014)

Thus the major concern in these guidelines was that low scores for EAL children would be 'unduly beneficial' to some schools, not that these scores might affect expectations for children. This appears to recognise that EAL children will be under-assessed through Baseline, but yet the focus of concern remains the 'accuracy' of the assessment, rather than the impact on children. Thus this policy text - like others on Baseline - maintains established ideas about EAL children as a statistical nuisance because they do not follow norms of progress. Further detailed analysis is necessary, but we can see these discourses as reinforcing the neutrality, centrality and thus dominance of whiteness.

\section{The context of practice}

Finally, the third context of practice is one where these key questions can be asked more directly. With a colleague, I conducted research into the introduction of Baseline in five 
schools across England, as it was introduced in the autumn of 2015 (Bradbury and RobertsHolmes 2016). Although there were EAL pupils at all the schools, one school (Cedar) had a high proportion of pupils learning English, and thus much of the interview data here relates to this school. The project also involved a nationwide survey of over a thousand teachers, which provided rich written responses (marked as $\mathrm{W}$ ) alongside the interviews with teachers, parents and school leaders.

The findings from this project allow us to further analyse the enactment of Baseline policy using the questions from the framework above. First, there was a clear impact on pedagogy and practice in general, but also specifically on how EAL learners were positioned:

The problem we have found this year is because we have to do it - it has to be conducted in English. I think that has impacted quite a bit. And normally for our on entry assessment we would - most of our support staff are bilingual and for the majority language here - so we would use that to inform our on entry assessments. (Assistant Head, Cedar)

For this senior leader, this policy marks a distinct shift in how they assess on entry, from using bilingual staff to attempt to gauge children's starting points to using an assessment which is entirely assessed in English. This is a shift which, to answer the second question of how the policy produces practices that result in disparities in attainment, creates results for EAL pupils which fail to reflect their abilities.

EAL children it was disadvantaging wasn't it, because you couldn't do it in another language, it had to be in English. (Teacher 2, Elm)

Now with the Baseline having to be conducted in English I think it will impact on the results. (Assistant Head, Cedar)

Not having any opportunity to note children with EAL is a concern as this will clearly mark them lower than necessary. (W) 
Baseline must be fair for EAL children - I had 6 this year, 3 of whom achieved less with Baseline Assessment but well in my own assessments as I allowed them to use their own language. (W)

This production of results which are inevitably lower for EAL children is done in a seemingly neutral manner, by simply assessing all children in the same way (in English). Previously the assessment in Reception emphasised that teachers should take into account children's skills and knowledge in their home language, while their levels of English are developing. As one teacher commented, the reliance of oral assessment is an issue:

It is always difficult with the EAL children because a lot of it is about can they speak about something. It's all about can they use mathematical language, but as the year goes on you get more from them. (Teacher 2, Cedar)

It seems like an unnecessary way of forcing us to make judgements which are extremely difficult to make in 3 weeks. So with our EAL children I can't make lots of judgements because their language is not good enough - so they get a no - but is that really reflective of that child? Too early to know. (W)

Thus the one-off nature of this assessment at the start of the year, in contrast to the ongoing observational assessment of the EYFS Profile, further limits how Baseline recognises what EAL children are capable of. This is a problem both for the observational forms of Baseline and the tablet-based versions:

I come from an inner city school with very high numbers of EAL children. The prescriptive questions detailing what you can/can't say meant that some things I knew my children would be able to do with a simplified instruction, they couldn't do as part of the baseline. (W)

Children who are EAL or didn't understand the question in a certain way were unable to answer questions correctly, affecting their scores. (W)

To answer the question of how policy encourage the use of stereotypes, dividing practices or 
labelling, in ways which disadvantaged minoritised students, I would argue that the labelling of EAL children as low-scoring on Baseline, although the data were not intended to be used for planning or grouping, has an impact on how they are constituted as learners. Being given a label of 'below expectations' has an impact even when the teacher recognises that this may be because of language issues. Thus the constitution of EAL children as lower-attaining, problematic learners, as found in research in many contexts (Leung, Harris, and Rampton 1997; Mitchell 2013), is solidified and made real by Baseline policy. Low results 'prove' that a particular intake is more challenging, even when teachers do not trust the scores.

Finally, we can see how the absence of 'race', or in this case non-majority languages (which may or may not be spoken by racialized minorities) perpetuates inequalities through the establishment of low expectations. The aim of Baseline was to set up a starting point, from which future performance can be judged. If this starting point is low, then this sets up low expectations for the child as they continue through the school. As the Headteacher at Cedar School commented:

\footnotetext{
You know you don't want limiting judgements at this point. Because obviously what you are looking to do is open potential up, and I know that sometimes by measuring that and saying you could have issues here it might enable you to do that, but actually it can lead to low expectations as well. So obviously what we are in the business of trying to do is identify the needs as early as possible, but what you are not wanting to do is to say this is happening here, therefore this is what we expect of you here; that might be too low. (Head, Cedar)
}

Low expectations are manifested in placement in 'lower ability' groups, differential activities and a restricted curriculum, and can lead to self-fulfilling prophecies. Furthermore, any system which measures 'value added', implicitly or explicitly engages in prediction of what is 'acceptable' or 'expected' progress. It is this expected progress which is used to assess what is better than normal or worse than normal progress. For EAL children, a low Baseline 
score, followed by expected progress, would mean low attainment at age 11 , without a concern being raised. The headteacher above continued:

But actually that worries me, I think there has been a real issue around target setting in terms of lower expectations, actually. Because you have hit your target you don't need to go higher, that somehow people don't work beyond that. [...] If you are looking at staff in schools and expectations of children, yes, I just have questions around that kind of information setting expectations for the future at that very early stage.

There is a risk that low attainment at later stages is explained away by EAL status, accepted and even expected, because it fits the model of predicted progress. The Reception teachers' doubts about accuracy will not be remembered when the child's progress is measured seven years later. This this policy sets up EAL children for school careers where they are never expected to catch up.

\section{Discussion}

In 2016 there were 118,030 children assessed in Reception who were listed as having a first language other than English, representing just under $18 \%$ of the total of 669,052 Reception children who were assessed through the EYFS Profile (DfE 2016). The proportion of these EAL children reaching the benchmark 'good level of development' (GLD) was $63 \%$, compared to $71 \%$ for those whose first language was English, even though the assessment can be conducted in part in home languages, where a translator is available. Thus this is a group of pupils who are already labelled as lower-attaining in this accountability-driven system, and yet a new policy was introduced which completely failed to take them into account. In retrospect, the teachers' concerns above seem obvious and predictable, and yet the issue of EAL children was completely omitted from policy documentation on Baseline. Moreover, when the policy was dropped in 2016, the explanation cited a report on the lack of 
comparability between the three assessments; EAL was not mentioned once (STA 2016).

Recent work on education policy and 'race' has critiqued the failure of policy makers to engage with the issue, and includes the suggestion that policy makers 'can't handle' the problem of racial inequality in education (Warmington et al. 2017). One might argue that 'handling' the problem of EAL children's attainment is easier, more palatable: after all, not speaking English is not a uniquely minoritised characteristic, as not all minoritized children are EAL, and not all EAL children are from minoritized groups. Furthermore, minoritised groups vary in the extent of their linguistic diversity (Demie 2015); the linguistic Other does not equate to the racialized Other. Moreover, it also seems like good pedagogical 'common sense' to consider those children who speak other languages at home in decisions about what happens in classrooms: this is not about culture, or background, but simply about language. Thus the failure to consider the impact on EAL children in Baseline policy is even more concerning; it suggest a concern with statistical accuracy (the need to find a 'true' baseline) over the impact on children at the very start of school. As such I would argue that it represents the worse dangers of a datafied system, where the production of numbers matters more than the social inequalities that result. Moreover, it can be seen as an act which perpetuates white dominance, because it systematically underestimates EAL children, many of whom come from minoritized communities. There is a tacit intentionality in failing to take account of the impact on EAL children of a new assessment, despite the duty for public bodies to consider the impact on different groups of new legislation (UK Government 2011). Back in 1999, House commented in his discussion of race and education policy that 'Americans will support policies that are harmful to minorities that they would not tolerate if those same policies were applied to majority populations' (p2); here we can apply the same logic, that many policy-makers (though perhaps not teachers and parents) in England will 
tolerate and even support policies that are harmful to EAL children, that they would not accept if the opposite were true.

Around the world, policies on EAL learners are 'wrought with contradiction' in that they glamorise bilingualism when it involves European languages and higher education, but reject immigrant languages (Leonardo and Hunter 2009, 157). With this in mind, Baseline Assessment in England can be seen as a policy which perpetuates the dominance of the English-speaking (mainly white) majority, through the under-assessment of the marginalised linguistic (and often racialized) Other. It remains to be seen how the new iteration of this policy, planned for 2020 after a series of pilots, will take into account the needs of EAL learners.

\section{Conclusion}

The analysis of education policy and its enactment in practice has long been concerned with the reproduction of inequalities through policy, and particularly assessment policy. Here I have attempted to use ideas from a highly influential body of work, Critical Race Theory, in combination with tools from policy sociology, specifically the policy cycle, to build a framework for analysing policy. This, I hope, begins to answer the question of what a distinctly CRT-based policy analysis would look like, and how it might differ from that with broader concerns, not rooted in a view of society where racism is 'business as usual' (Delgado and Stefancic 2000). This adds to work such as that of Atwood and Lopez (2014), who set out how CRT methodologies such as counterstories can 'complicate our understanding of "truth" in policy.

In education, policy is always political: it shapes subjectivities, produces discourses of success and failure, and determines practices and priorities, all in ways which work to advantage some students over others. As Gillborn argues 'although race inequity may not be a planned and deliberate goal of education policy neither is it accidental' $(2005,485)$; there 
are many who gain from the continued inequalities that exist within the education system. The focus in critical policy analysis on what is absent (Diem et al. 2014) is crucial here in exploring how racial inequities are maintained. At all stages of the policy cycle, those who are already marginalised are further disadvantaged by policies, such as Baseline Assessment, which fail to address racial inequalities, instead pushing this concern to the periphery of political debate. Thus it is vital that policy analysis - in all forms - should re-centre this concern and draw attention to the role of policy, and the policy-makers themselves, in reproducing racial inequality.

\section{References}

Apple, Michael W. 1999. "The absent presence of race in educational reform." Race, Ethnicity and Education 2 (1):9 - 16.

Atwood, E. and G.R. López. 2014. Let's be critically honest: Towards a messier counterstory in critical race theory. International Journal of Qualitative Studies in Education 27, no 9: 1134-54.

Ball, Stephen 2013b. The education debate (2nd edition), Policy and politics in the twentyfirst century. Bristol: Policy Press.

Ball, Stephen J. 1993. "What is policy? Texts, trajectories and toolboxes." Discourse: studies in the cultural politics of education 13 (2):10-7. doi: 10.1080/0159630930130203.

Ball, Stephen J., Meg Maguire, Annette Braun, and Kate Hoskins. 2011. "Policy subjects and policy actors in schools: some necessary but insufficient analyses." Discourse: studies in the cultural politics of education 32 (4):611-24. doi:

10.1080/01596306.2011.601564.

Ball, Stephen. 2013a. Foucault, Power and Education. Abingdon: Routledge.

BBC News, 'Stephen Lawrence Day to be held annually', Accessed 27 September 2018 https://www.bbc.co.uk/news/uk-43869377

Bell, Derrick. 1992. Faces at the bottom of the well: the permanence of racism. New York: BasicBooks.

Bell, Les, and Howard Stevenson. 2006. Education policy: Process, themes and impact: Routledge. 
Bonilla-Silva, E. 2015. More than prejudice: Restatement, reflections, and new directions in critical race theory. Sociology of Race and Ethnicity 1, no 1: 73-87.

Bowe, R, S Ball, and A Gold. 1992. Reforming education and changing schools: Case studies in policy sociology London Routledge.

Bradbury, A. 2013. From model minorities to disposable models: The de-legitimisation of educational success through discourses of authenticity. Discourse: studies in the cultural politics of education 34, no 4: 548-61.

Bradbury, Alice, and Guy Roberts-Holmes. 2016. "'They are children, not robots': The Introduction of Baseline Asssessment." London: ATL/NUT.

Bradbury, Alice, and Guy Roberts-Holmes. 2017. The Datafication of Early Years and Primary Education: Playing with numbers, Routledge.

Bradbury, Alice. 2011a. "Equity, ethnicity and the hidden dangers of 'contextual' measures of school success." Race, Ethnicity and Education 14 (3):277 - 91.

Bradbury, Alice. 2011b. "Rethinking assessment and inequality: the production of disparities in attainment in early years education." Journal of Education Policy 26 (5):655 - 76.

Bradbury, Alice. 2013. Understanding Early Years Inequality: policy, assessment and young children's identities. London: Routledge.

Braun, Annette, M. Maguire, and Stephen Ball. 2012. How Schools Do Policy: Policy Enactments in Secondary Schools.

Braun, Annette, Stephen J. Ball, Meg Maguire, and Kate Hoskins. 2011. "Taking context seriously: towards explaining policy enactments in the secondary school." Discourse: studies in the cultural politics of education 32 (4):585-96. doi:

10.1080/01596306.2011.601555.

Campbell, Tammy. 2015. "Stereotyped at Seven? Biases in Teacher Judgement of Pupils' Ability and Attainment." Journal of Social Policy 44 (03):517-47. doi: doi:10.1017/S0047279415000227.

Chadderton, C. 2015. UK secondary schools under surveillance: What are the implications for race? A critical race and Butlerian analysis. In Power and education, 128-45: Springer.

Chadderton, Charlotte. 2014. "The militarisation of English schools: Troops to Teaching and the implications for Initial Teacher Education and race equality." Race Ethnicity and Education 17 (3):407-28. 
Chapman, Thandeka K., and Jamel K. Donnor. 2015. "Critical Race Theory and the Proliferation of U.S. Charter Schools." Review of. Equity \& Excellence in Education 48 (1):137-57. doi: 10.1080/10665684.2015.991670.

D'Arcy, K. 2014. Educational inclusion: Meeting the needs of all traveller pupils. In Advancing race and ethnicity in education, eds Race, R and Lander, V. Basingstoke: PalgraveMacmillan.

Delgado, Richard, and Jean Stefancic. 2000. Critical Race Theory: The Cutting Edge. Philadelphia: Temple University Press.

Demie, Feyisa. 2015. "Language diversity and attainment in schools: implication for policy and practice." Race Ethnicity and Education 18 (5):723-37. doi: 10.1080/13613324.2014.946493.

DfE 2017. "Statutory Framework for the Early Years Foundation Stage." https://www.foundationyears.org.uk/files/2017/03/EYFS_STATUTORY_FRAMEW ORK_2017.pdf.

DfE. 2015 "Policy paper: 2010 to 2015 government policy: school and college funding and accountability." Accessed 14 January 2018. https://www.gov.uk/government/publications/2010-to-2015-government-policyschool-and-college-funding-and-accountability/2010-to-2015-government-policyschool-and-college-funding-and-accountability\#appendix-2-reception-baselineassessment.

DfE. 2016. "Early Years Foundation Stage Profile Results in England, 2015/16: SFR 50/2016." Department for Education, Accessed 19 January 2017. https://www.gov.uk/government/statistics/early-years-foundation-stage-profileresults-2015-to-2016.

Diem, S., M.D. Young, A.D. Welton, K.C. Mansfield and P.-L. Lee. 2014. The intellectual landscape of critical policy analysis. International Journal of Qualitative Studies in Education 27, no 9: 1068-90.

Foucault, M. 1980. Power-knowledge: Selected interviews and other writings, 1972-1977. Brighton: Harvester Press.

Gale, Trevor. 1999. "Policy Trajectories: treading the discursive path of policy analysis." Discourse: studies in the cultural politics of education 20 (3):393-407. doi: 10.1080/0159630990200304.

Gewirtz, Sharon, Marny Dickson, and Sally Power. 2007. "Unravelling a 'spun' policy: a case study of the constitutive roel of 'spin' in the education policy process." In The 
RoutledgeFalmer Reader in Education Policy and Politics, edited by B Lingard and Jennifer Ozga. Abingdon: Routledge.

Gillborn, D. 2010. The white working class, racism and respectability: Victims, degenerates and interest-convergence. British Journal of Educational Studies 58, no 1: 3-25.

Gillborn, D., P. Warmington and S. Demack. 2018. Quantcrit: Education, policy, 'big data' and principles for a critical race theory of statistics. Race Ethnicity and Education: 158-79.

Gillborn, David, and Deborah Youdell. 2000. Rationing education: policy, practice, reform and equity. Buckingham: Open University Press.

Gillborn, David, Sean Demack, Nicola Rollock, and Paul Warmington. 2017. "Moving the goalposts: Education policy and 25 years of the Black/White achievement gap." British Educational Research Journal 43(5), 848-874

Gillborn, David. 2005. "Education policy as an act of white supremacy: whiteness, critical race theory and education reform." Journal of Education Policy 20 (4):485-505. doi: $10.1080 / 02680930500132346$.

Gillborn, David. 2008. Racism and education: coincidence or conspiracy? London: Routledge.

Gillborn, David. 2013a. "Interest-divergence and the colour of cutbacks: race, recession and the undeclared war on Black children." Discourse: studies in the cultural politics of education 34 (4):477-91. doi: 10.1080/01596306.2013.822616.

Gillborn, David. 2013b. "Racism as Policy: A Critical Race Analysis of Education Reforms in the United States and England." The Educational Forum 78 (1):26-41. doi: 10.1080/00131725.2014.850982.

House, E.R. 1999. Race and policy. education policy analysis archives 7: 16.

Jarvis, Pam. "Is baseline missing the bigger picture?", Accessed 14 January 2018. https://www.tes.com/news/school-news/tes-magazine/baseline-missing-biggerpicture.

Ladson-Billings, Gloria. 2004. "Just what is Critical Race Theory and what's it doing in a nice field like education? ." In The RoutledgeFalmer Reader in Multicultural Education, edited by Gloria Ladson-Billings and David Gillborn. Abingdon: RoutledgeFalmer.

Leonardo, Z. 2004. "The Color of Supremacy: Beyond the discourse of 'white privilege'." Educational Philosophy and Theory 36 (2):137 - 52. 
Leonardo, Z. 2007. "The war on schools: NCLB, nation creation and the educational construction of whiteness." Race, Ethnicity and Education 10 (3):262 - 78.

Leonardo, Zeus, and M Hunter. 2009. "Race, class and imagining the urban." In Race, Whiteness and Education, edited by Zeus Leonardo. New York: Routledge.

Leung, Constant, Roxy Harris, and Ben Rampton. 1997. "The Idealized Native Speaker, Reified Ethnicities, and Classroom Realities." TESOL Quarterly 31 (3):543-60.

Lightfoot, Nic. 2015. "Policy research: in defence of ad hocery?" In Exploring education at postgraduate level: policy, theory and practice, edited by Anne O'Grady and Vanessa Cottle. London: Routledge.

Liu, Yongcan, and Michael Evans. 2016. "Multilingualism as legitimate shared repertoires in school communities of practice: students' and teachers' discursive constructions of languages in two schools in England." Cambridge Journal of Education 46 (4):55368. doi: 10.1080/0305764X.2015.1091441.

McGillicuddy, Deirdre, and Dympna Devine. 2018. "“Turned off" or "ready to fly" - Ability grouping as an act of symbolic violence in primary school." Teaching and Teacher Education 70:88-99. doi: https://doi.org/10.1016/j.tate.2017.11.008.

McGimpsey, Ian, Alice Bradbury, and Diego Santori. 2017. "Revisions to rationality: the translation of 'new knowledges' into policy under the Coalition Government." British Journal of Sociology of Education 38 (6):908-25. doi:

10.1080/01425692.2016.1202747.

Michelle D. Young \& Sarah Diem (2014) Putting critical theoretical perspectives to work in educational policy, International Journal of Qualitative Studies in Education, 27:9, 1063-1067, DOI: 10.1080/09518398.2014.916015

Mitchell, Kara. 2010 Systemic inequities in the policy and practice of educating secondary bilingual learners and their teachers: A critical race theory analysis. Boston College. ProQuest Dissertations and Theses 543

Mitchell, Kara. 2013. "Race, difference, meritocracy, and English: majoritarian stories in the education of secondary multilingual learners." Race Ethnicity and Education 16 (3):339-64. doi: 10.1080/13613324.2011.645569.

Moss, Peter, Gunilla Dahlberg, Susan Grieshaber, Susanna Mantovani, Helen May, Alan Pence, Sylvie Rayna, Beth Blue Swadener, and Michel Vandenbroeck. 2016. "The Organisation for Economic Co-operation and Development's International Early Learning Study: Opening for debate and contestation." Contemporary Issues in Early Childhood 17 (3):343-51. doi: 10.1177/1463949116661126. 
Moss, Peter. 2014. Transformative Change and Real Utopias in Early Childhood Education: A story of democracy, experimentation and potentiality. Oxon: Routledge.

NALDIC. "The EAL Learner: Research and Statistics." Accessed 14 January 2018. https://naldic.org.uk/the-eal-learner/.

Parker, Laurence. "Critical race theory and its implications for methodology and policy analysis in higher education desegregation." Counterpoints 195 (2003): 145-180.

Rizvi, Fazal, and Bob Lingard. 2009. Globalizing education policy: Routledge.

Sarah Diem, Michelle D. Young, Anjalé D. Welton, Katherine Cumings Mansfield \& PeiLing Lee (2014) The intellectual landscape of critical policy analysis, International Journal of Qualitative Studies in Education, 27:9, 1068-1090, DOI: $10.1080 / 09518398.2014 .916007$

Scott, J. \& Holme, J. J. (2016) The political economy of market-based educational policies:Race and reform in urban school districts, 1915 to 2016. Review of Research in Education, 40(1), 250-297.

Scott, Janelle T. 2011. "Market-Driven Education Reform and the Racial Politics of Advocacy." Review of. Peabody Journal of Education 86 (5):580-99. doi: 10.1080/0161956X.2011.616445.

Sellar, Sam, and Bob Lingard. 2014. "The OECD and the expansion of PISA: New global modes of governance in education." British Educational Research Journal 40 (6):917-36.

STA. 2014. "Reception baseline: criteria for potential assessments." Standards and Testing Agency.

STA. 2016 "Reception baseline comparability study." Standards and Testing Agency, Accessed 6 April 2017. https://www.gov.uk/government/publications/receptionbaseline-comparability-study.

Tate, W.F. 1997. "Critical Race Theory and Education: History, theory and implications." In Review of Research in Education, edited by Michael W. Apple. Washington DC: American Educational Research Association.

Taylor, Edward, David Gillborn, and Gloria Ladson-Billings. 2009. Foundations of critical race theory in education. New York; London: Routledge.

Tereshchenko, A., Bradbury, A. and Archer, L. (2019) Eastern European Migrants' Experiences of Racism in English Schools: Positions of Linguistic Otherness and Marginal Whiteness Whiteness and Education https://doi.org/10.1080/23793406.2019.1584048 
UK Government. "Public sector: quick start guide to the public sector Equality Duty." Accessed 25 January 2018. https://www.gov.uk/government/publications/publicsector-quick-start-guide-to-the-public-sector-equality-duty.

UK Government. "Race Disparity Audit." Accessed 14 January 2018. https://www.gov.uk/government/publications/race-disparity-audit.

Warmington, Paul, David Gillborn, Nicola Rollock, and Sean Demack. 2017. "“They can't handle the race agenda": stakeholders' reflections on race and education policy, 1993-2013." Educational Review 70 (4) 409-426 doi: 10.1080/00131911.2017.1353482.

Welply, Oakleigh. 2017. "'My language ... I don’t know how to talk about it': children's views on language diversity in primary schools in France and England." Language and Intercultural Communication 17 (4):437-54. doi: 10.1080/14708477.2017.1368145.

Yosso, Tara J. 2005. "Whose culture has capital? A critical race theory discussion of community cultural wealth." Race Ethnicity and Education 8 (1):69-91. doi: 10.1080/1361332052000341006.

Young, M.D. and S. Diem. 2014. Putting critical theoretical perspectives to work in educational policy. International Journal of Qualitative Studies in Education 27, no 9: 1063-67.

\footnotetext{
${ }^{i}$ Note that in later work Ball has added to this model but for the purposes of this discussion I will focus on the original three contexts.
} 